\title{
KEMANGKUSAN Metarhizium anisoplae DAN Beauveria ba ssiana SEBAGAI BIOINSEKTISIDA BAGI HAMA GUDANG Sitophilus oryzae
}

\author{
The effectiveness of Metarhizium anisopliae and Beauveria bassiana as Bioinsecticides for \\ Pest Warehouse Sitophilus oryzae \\ Mohammad Akhbar Yassin ${ }^{1 *}$, Nur Rochman ${ }^{2}$, Setyono $^{2}$ \\ ${ }^{1}$ Program Studi Agroteknologi, Fakultas Pertanian, Universitas Djuanda \\ ${ }^{2}$ Staf Pengajar Program Studi Agroteknologi, Fakultas Pertanian, Universitas Djuanda \\ Jl. Tol Ciawi 1, Kotak Pos 35 Bogor 16720 \\ "Email : akhbaryassin@gmail.com
}

\section{Diterima 17 April 2020/Disetujui 30 April 2020}

\begin{abstract}
ABSTRAK
Sitophilus oryzae merupakan hama gudang yang menyerang beras (Oryza sativa). Salah satu cara pengendalian yang dapat digunakan yaitu memanfaatkan agen hayati sebagai pengendali hama tersebut di antaranya Metarhizium anisopliae dan Beauveria bassiana. Penelitian ini menggunakan rancangan acak lengkap (RAL) 2 percobaan yang memiliki 5 taraf perlakuan yang digunakan yaitu $0,10^{6}, 10^{7}, 10^{8}$ dan $10^{9}$ konidia $\mathrm{ml}^{-1}$ pada masingmasing percobaan. Imago $S$. oryzae diberi perlakuan suspensi konidia $M$. anisopliae dan $B$. Bassiana masing-masing pada kerapatan 0 (kontrol), 0, 10 $0^{6}, 10^{7}, 10^{8}$ dan $10^{9}$ konidia $\mathrm{ml}^{-1}$. Aplikasi dilakukan dengan metode semprot terhadap serangga. Dengan kerapatan konidia $10 \% / \mathrm{ml}$ cendawan $M$. anisopliae hanya mampu mengakibatkan kematian $S$. oryzae hingga $33,3 \%$ pada hari ke-10 setelah perlakuan. Garis persamaan regresi polinomial yang dihasilkan pada hari ke-10 setelah perlakuann adalah $0,0615 x^{2}+1,8386 x+5,6936$ dengan $R^{2}=0,8194$. Karena nilai mortalitas maksimum yang didapatkan sebesar $33,3 \%$, sehingga $\mathrm{LC}_{50}$ dan $\mathrm{LC}_{95}$ tidak dapat dihitung. Sedangkan $B$. Bassiana mampu mengakibatkan kematian S. oryzae hingga $98,8 \%$ pada hari ke-10 setelah perlakuan. Garis persamaan regresi polinomial yang dihasilkan pada 10 HSP adalah $\mathrm{y}=-0,4209 \mathrm{x}^{2}+14,38 \mathrm{x}+5,3044$ dengan $\mathrm{R}^{2}=0,9792$. Menurut persamaan tersebut, nilai mortalitas maksimum yang didapatkan adalah sebesar $128 \%$, sehingga $\mathrm{LC}_{50}$ dan $\mathrm{LC}_{95}$ dapat dihitung. Konsentrasi yang efektif untuk mencapai $\mathrm{LC}_{50}$ adalah sebesar $1 \times 10^{3}$ konidia/ml dan konsentrasi yang efektif untuk mencapai $\mathrm{LC}_{95}$ adalah $1 \times 10^{8} \mathrm{konidia} / \mathrm{ml}$. Dari hasil yang diperoleh dapat disimpulkan bahwa penggunaan cendawan B. Bassiana lebih efektif untuk mematikan $S$. oryzae
\end{abstract}

Kata kunci : kerapatan konidia, beras, bioinsektisida, Sitophilus oryzae

\section{ABSTRACT}

Sitophilus oryzae is a warehouse pest that attacks rice-pant (Oryza sativa). It can be controlled by utilizing biological agents as these pests controller, amongst those can be used such as Metarhizium anisoplae and Beauveria bassiana. The purpose of this research are to determine the effectiviness of Metarhizium anisoplae and Beauveria bassiana's attacks on Sitophilus oryzae. The research's method consist of two experiments, each using Completely Randomized Design with 5 treatment degree wich are $O$ (control) $10^{6}, 10^{7}, 10^{8}$, and $10^{9}$ conidia/ml, each degree has 3 repetitions. Applications is implemented by spray method on insects. At dencity concentration of $10^{9}$ conidia/ml Metarhizium anisoplae only able to inflict death of Sitophilus oryzae up to $33,33 \%$ on the $10^{\text {th }}$ after treatment. Based on variety 
analysis the values cant't be achieved. Meanwhile, Beauveria bassiana was able to inflict death on Sitophilus oryzae up to $98 \%$ on the $10^{\text {th }}$ after treatment. Therefore Lethal Concentration $L C_{50}$ and $L C_{95}$ can be achieved. The effective concentration to achieve $L C_{50}$ is $2 \times 10^{3}$ conidia/ml and $L C_{95}$ is $1,5 \times 10^{8}$ conidia/ml. Therefore, the use of Beauveria bassiana is more effective to kill Sitophilus oryzae.

Keywords: conidia density, rice-plant, bioinsecticide, Sitophilus oryzae

\section{PENDAHULUAN}

Kebutuhan beras di Indonesia setiap tahunnya mengalami peningkatan. Menurut data badan pusat statistika Indonesia (BPS) produksi beras di Indonesia sejak tahun 2011 hingga 2017 mengalami kenaikan yakni sebesar 65,75 juta ton pada tahun 2011 dan 82,38 juta ton pada tahun 2017 (BPS 2018).

Faktor gudang mempunyai peran yang penting untuk ketersediaan beras. Menjaga agar gudang terbebas dari hama gudang merupakan hal yang penting. Hama Sitophilus oryza merupakan hama primer yang menyerang beras, sorgum, gandum, dan jagung di tempat penyimpanan (Longstaff 1981). Akibat serangan hama, beras yang disimpan dalam gudang dapat mencapai kerusakan sebesar $10-20 \%$ dari keseluruhan produksi (Phillips dan Throne 2010).

Pada umumnya pengendalian hama di gudang beras dilakukan dengan dua cara yaitu dengan penyemprotan pestisida kimia kontak dan fumigasi. Penggunaan pestisida dalam jangka waktu yang lama dapat mencemari lingkungan sedangkan penggunaan fumigasi hanya efektif pada saat pelaksanaan dan dilakukan pada tempat tertutup dan kedap udara (ACIAR 2007).

Penggunaan agen hayati cendawan entomopatogen merupakan suatu upaya untuk mengurangi penggunaan pestisida sintetik yang selama ini banyak menyebabkan permasalahan lingkungan, dan diharapkan menjadi solusi sekaligus dapat menggali potensi dasar hayati yang telah ada (Desyanti et al. 2007). Beberapa spesies cendawan entomopatogen yang dapat dipertimbangkan menjadi insektisida biologis adalah Beauveria bassiana, Metarhizium anisopliae, Verticillium lecanii, dan Hirsutella thompsonii (Wahyono dan Tarigan 2007). Jamur Metarhizium anisopliae dapat menginfeksi serangga dari kelompok ordo Orthoptera, Coleoptera, Hemiptera, Lepidoptera dan Hymenoptera (Lee dan Hou 2003).

Berdasarkan uraian di atas maka dilakukan penelitian tentang pengendalian hama secara hayati dengan menggunakan jamur entomopatogen (Metarhizium anisoplae dan Beauveria bassiana) untuk mencari konsentrasi atau kerapatan konidia yang tepat dalam mengendalikan hama gudang Sitophilus oryzae. Tujuan penelitian ini adalah mengetahui kemangkusan atau keefektifan serangan Metarhizium anisoplae dan Beuaveria bassiana terhadap hama gudang Sitophilus oryzae

\section{BAHAN DAN METODE}

\section{Waktu dan Tempat}

Penelitian dilaksanakan pada bulan Januari hingga April 2019 di Laboratorium Entomologi dan Fitopatologi, SEAMEO BIOTROP, Jl. Raya Tajur km 6, Bogor.
Alat dan Bahan
penelitian
Alat-alat yang digunakan selama pengembangbiakan serangga, cawan petri, timbangan, gelas beker, erlenmeyer, corong, pipet, botol semprot, jarum ose, mikroskop, haemocytometer, oven, tabung berskala, autoclave SN 90, inkubator. Bahan-bahan yang digunakan selama penelitian adalah hama gudang $S$. oryzae, cendawan $B$. bassiana, $M$. anisopliae, 
media Pottato Dextrose Agar (PDA), tween 80 , aquades, tisu dan kain batis.

\section{Rancangan Percobaan}

Penelitian ini terdiri atas 2 percobaan yaitu percobaan I untuk mengetahui pengaruh kerapatan konidia cendawan $M$. anisopliae dan percobaan II untuk mengetahui pengaruh kerapatan konidia cendawan $B$. bassiana sebagai agen hayati pengendali Sitophilus oryzae. Masing-masing percobaan menggunakan rancangan acak lengkap (RAL) dengan 5 taraf perlakuan yaitu $0,10^{6}, 10^{7}, 10^{8}$, $10^{9}$ konidia $\mathrm{ml}^{-1}$ ). Setiap taraf perlakuan menggunakan tiga ulangan.

\section{Analisis Data}

Persentase kematian Sitophilus oryzae menggunakan rumus:

Keterangan:

$$
\mathrm{P}=\frac{\mathrm{n}}{\mathrm{N}} \times \mathbf{1 0 0} \%
$$

$\mathrm{P}=$ Persentase kematian

$\mathrm{n}=$ Jumlah individu yang mati

$\mathrm{N}=$ Jumlah individu yang digunakan

Hasil persentase kematian kemudian ditransformasikan ke dalam $\operatorname{arc} \sin \sqrt{\mathrm{y}}$ dan diolah menggunakan analisis ragam. Apabila pengaruh kerapatan konidia terhadap mortalitas $S$. oryzae bersifat nyata maka selanjutnya dilakukan analisis regresi polinomial untuk mengetahui nilai maksimum dan Lethal Concentration $\left(\mathrm{LC}_{50}\right.$ dan $\left.\mathrm{LC}_{95}\right)$.

\section{Pembuatan Isolat dan Penyiapan Suspensi Cendawan}

Isolat diperbanyak dengan menggunakan media PDA pada cawan petri berukuran $100 \mathrm{~mm}$ x $20 \mathrm{~mm}$. Komposisi media PDA adalah kentang, agar, dextrose, dan chloramphenicol. Setelah inokulasi, cendawan ditumbuhkan dalam inkubator dengan suhu $28^{\circ} \mathrm{C}$.
Metarhizium anisopliae dan Beauveria bassiana yang telah berumur 21 hari setelah inokulasi (HSI) diambil konidianya dengan cara mengambil area pertumbuhan cendawan pada media agar dengan menggunakan spatula steril. Cendawan dicampur dengan akuades steril yang telah ditambahkan tween 80 lalu disaring untuk mendapatkan suspensi konidia yang jernih. Kerapatan konidia dihitung menggunakan haemocytometer neubaur improved.

\section{Perlakuan Serangga Uji}

Langkah pertama pada perlakuan serangga uji adalah dengan menyiapkan 30 cawan berukuran $150 \mathrm{~mm}$ x $25 \mathrm{~mm}$ untuk masing-masing cawan yang akan diisi oleh imago $S$. oryzae. Setiap cawan tersebut diisi oleh $S$. oryzae masing-masing sebanyak 20 ekor. Dasar cawan diletakan tisu yang telah disterilisasi kemudian dibasahi agar ruangan cawan memiliki kelembaban yang cukup untuk pertumbuhan cendawan. Suspensi yang telah dibuat kemudian disemprotkan terhadap serangga yang berada di cawan sebanyak $1 \mathrm{ml}$ volume semprot. Masingmasing aplikasi taraf perlakuan menggunakan tiga kali ulangan. Perlakuan kontrol dilakukan dengan cara menyemprotkan akuades steril yang telah ditambah Tween80. Pengamatan dilakukan dengan menghitung jumlah $S$. oryzae yang mati pada 1-10 hari setelah perlakuan (HSP).

\section{HASIL DAN PEMBAHASAN}

Secara umum dari data yang diperoleh menunjukkan bahwa semakin tinggi tingkat kerapatan konidia yang digunakan, maka semakin tinggi mortalitas S. Oryzae yang dihasilkan (Tabel 1). 
Tabel 1 Mortalitas S. Oryzae pada hari ke-10 setelah perlakuan M. anisopale dan B. Bassiana Mortalitas S. Oryzae (\%)

\begin{tabular}{ccc} 
Kerapatan Konidia $\mathrm{ml}^{-1}$ & Aplikasi M. anisopliae & Aplikasi B. bassiana \\
\hline 0 & 5,50 & 5,50 \\
$10^{6}$ & 21,1 & 71,1 \\
$10^{7}$ & 20,0 & 92,2 \\
$10^{8}$ & 22,2 & 93,3 \\
$10^{9}$ & 28,2 & 98,8 \\
\hline
\end{tabular}

Korelasi antara log konsentrasi kerapatan konidia $M$. anisopliae dengan mortalitas $S$. oryzae adalah 0,98 dan korelasi antara log konsentrasi kerapatan konidia $B$. bassiana dengan mortalitas $S$. oryzae adalah 0,99. Berdasarkan kedua korelasi tersebut maka disimpulkan terdapat hubungan yang sangat kuat antara kerapatan konidia dengan mortalitas $S$. oryzae baik menggunakan cendawan $M$. anisopliae maupun B. bassiana. Namun pada konidia $B$. bassiana mortalitas $S$. oryzae relatif tinggi sedangkan pada konidia $M$. anisopliae mortalitas $S$. oryzae masih rendah.

Berdasarkan tabel di atas, terdapat perbedaan tingkat mortalitas serangga yang diakibatkan oleh cendawan M.anisopliae dan B.bassiana. Pada aplikasi menggunakan cendawan M.anisopliae mortalitas tertinggi hanya mencapai $28,2 \%$ terjadi pada kerapatan $1 \times 10^{9}{\text { konidia } \mathrm{ml}^{-1}}^{-}$ dan mortalitas terendah mencapai $21,1 \%$ pada kerapatan $1 \times 10^{6}$ konidia $\mathrm{ml}^{-1}$. Pada aplikasi cendawan B.bassiana pada 10 HSP mortalitas tertinggi mencapai $98,8 \%$ terjadi pada kerapatan konidia $1 \times 10^{9}$ konidia $\mathrm{ml}^{-1}$ dan mortalitas terendah mencapai $71,1 \%$ pada kerapatan konidia $1 \times 10^{6}$ konidia $\mathrm{ml}^{-1}$.

Menurut Bari (2006), tingkat kematian Cylas formaricarius yang disebabkan oleh B.bassiana pada kerapatan konidia $10^{8} \mathrm{ml}^{-1}$ pada hari ke-6 sampai ke10 hampir $100 \%$. Pada penelitian ini dengan tingkat kerapatan konidia $1 \times 10^{8}$ $\mathrm{ml}^{-1}$ pada $10 \mathrm{HSP}$ menggunakan cendawan $M$. anisopliae dapat mematikan $S$. oryzae sebesar $22,2 \%$, sedangkan menggunakan cendawan $B$. bassiana dapat mematikan $S$. oryzae sebesar 93,3\%. Pada Gambar 1 dan Gambar 2 disajikan mortalitas kumulatif $S$. oryzae yang terserang cendawan $M$. anisopliae dan B. Bassiana.

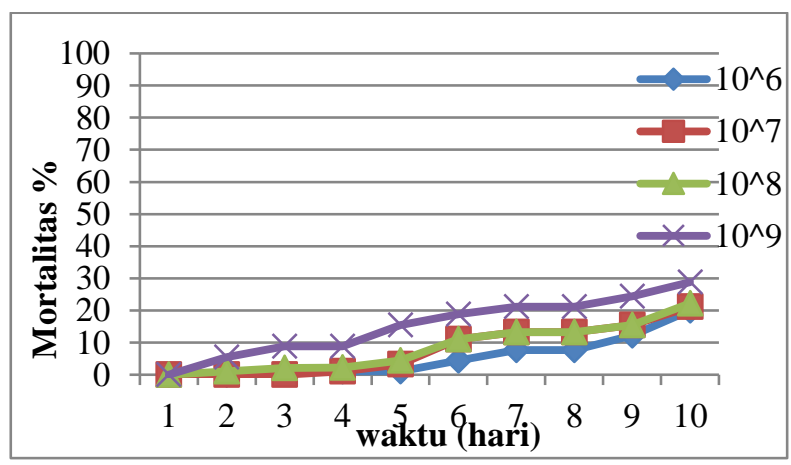

Gambar 1 Mortalitas kumulatif S.oryzae yang terinfeksi M.anisopliae selama 10 HSP

Pada awal perlakuan serangga mulai menunjukkan ciri-ciri terinfeksi dengan $1-2 \%$ tingkat kematian oleh cendawan B.bassiana pada kerapatan $1 \times 10^{9}$ konidia $\mathrm{ml}^{-1}$, sedangkan cendawan
M.anisopliae mulai menginfeksi pada hari ke-2 dengan tingkat kematian serangga mencapai $5,5 \%$ pada kerapatan $1 \times 10^{9}$ konidia $\mathrm{ml}^{-1}$. S. Oryzae yang terinfeksi cendawan $B$. bassiana mengalami 
mortalitas lebih tinggi setelah pengamatan hari ke-10. Menurut Riyanto dan Santoso (1991), gerakan serangga yang terinfeksi menjadi lamban, nafsu makan berkurang bahkan berhenti, lama kelamaan diam dan mati sehingga tubuhnya diselimuti oleh hifa (Gambar 3). Jumlah konidia mempengaruhi mortalitas hama tersebut, semakin tinggi kerapatan konidia semakin tinggi mortalitas hama.

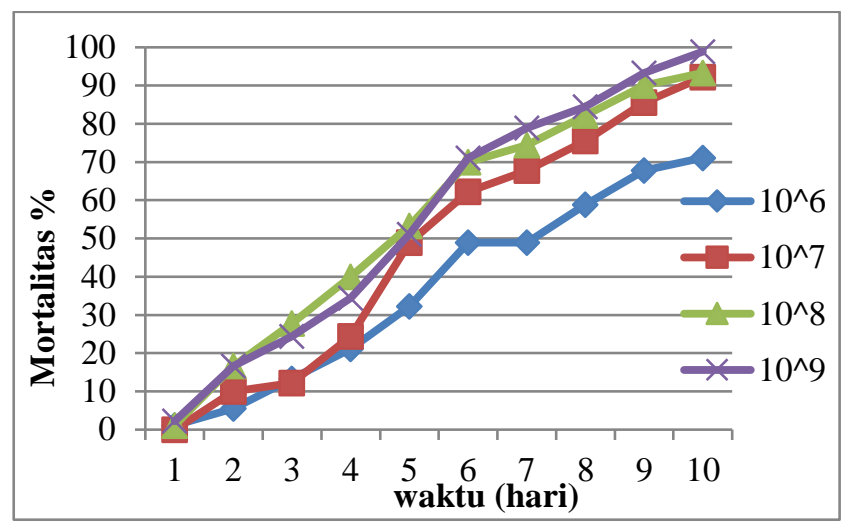

Gambar 2 Mortalitas kumulatif S.oryzae yang terinfeksi B. Bassiana selama 10 HSP

Lethal concentration (LC) adalah nilai yang menunjukkan jumlah racun per satuan berat yang dapat mematikan populasi hewan yang digunakan dalam percobaan (Prijono 1985). Untuk mengetahui LC pada suatu cendawan maka perlu diketahui fungsi mortalitas cendawan terhadap konsentrasi yang diaplikasikan.
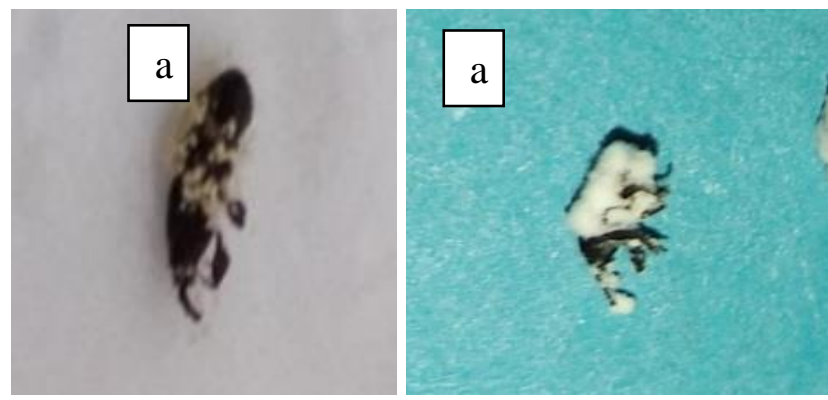

Gambar 3 Serangga terinfeksi. a. Serangga terinfeksi $M$. anisopliae, b. serangga terinfeksi $B$. bassiana

\section{Mortalitas Hama oleh $M$. anisopliae pada 10 HSP}

Pada aplikasi cendawan $M$. anisopliae berdasarkan hari ke-1 sampai hari ke-10 setelah perlakuan tidak dapat dicari $\mathrm{LC}_{50}$ dan $\mathrm{LC}_{95}$ karena nilai maksimum tidak mencapai $50 \%$. Nilai mortalitas tertinggi pada hari ke- 1 sebesar nol, hari ke-2 sebesar 6,6\%, hari ke-3 sebesar $10 \%$, hari ke-4 sebesar $10 \%$, hari ke-5 sebesar 20\%, hari ke-6 sebesar $20 \%$, hari ke-7 sebesar $26,7 \%$, hari ke- 8 sebesar $26,7 \%$, hari ke-9 sebesar 26,7\%. Dari keseluruhan hari, nilai mortalitas tertinggi terdapat pada 10 HSP sebesar 33,3\%. Mortalitas hama $S$. oryzae pada 10 HSP tersaji pada Gambar 4. Analisis ragam (Uji F) menunjukkan bahwa kerapatan konidia dari cendawan M.anisoplae berpengaruh terhadap mortalitas hama $S$. oryzae. Garis persamaan regresi polinomial yang dihasilkan pada 10 HSP adalah $\mathrm{y}=$ $0,0615 x^{2}+1,8386 x+5,6936$ dengan $R^{2}=$ 0,8194 . Karena nilai mortalitas maksimum yang didapatkan hanya sebesar $33,3 \%$, maka $\mathrm{LC}_{50}$ dan $\mathrm{LC}_{95}$ tidak dapat dihitung. 


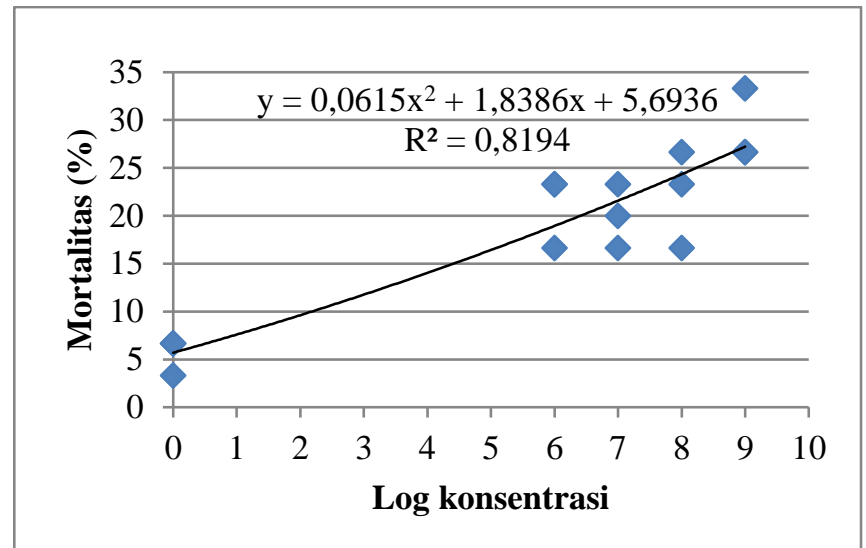

Gambar 4 Persamaan regresi pada 10 HSP pada pengujian cendawan M.anisoplae

\section{Mortalitas Hama oleh B. bassiana pada 5 HSP}

Pada hari ke-1setelah perlakuan nilai mortalitas maksimum sebesar 3,3\%, hari ke-2 sebesar $20 \%$, hari ke-3 sebesar $26,7 \%$, dan hari ke-4 sebesar $36,7 \%$ sehingga pada hari ke-1 sampai hari ke-4 tidak dapat dicari $\mathrm{LC}_{50}$ dan $\mathrm{LC}_{95}$. Oleh sebab itu pencarian $\mathrm{LC}_{50}$ dan $\mathrm{LC}_{95}$ dimulai pada 5 HSP hingga $10 \mathrm{HSP}$.

Analisis ragam (Uji $\mathrm{F})$ menunjukkan bahwa kerapatan konidia dari cendawan B.bassiana berpengaruh terhadap mortalitas hama S.oryzae. Garis persamaan regresi polinomial yang dihasilkan pada 5 HSP adalah $\mathrm{y}=$ $0,0818 \mathrm{x}^{2}+6,8897 \mathrm{x}-0,3492$ dengan $\mathrm{R}^{2}=$ 0,9301 (Gambar 5).

Menurut persamaan tersebut, nilai mortalitas maksimum yang didapatkan adalah sebesar 144,72\%, sehingga $\mathrm{LC}_{50}$ dan $\mathrm{LC}_{95}$ dapat dicari. Konsentrasi yang efektif untuk mencapai $\mathrm{LC}_{50}$ adalah sebesar $1 \times 10^{8}$ konidia $\mathrm{ml}^{-1}$ dan konsentrasi yang efektif untuk mencapai $\mathrm{LC}_{95}$ adalah $1 \times 10^{17}$ konidia $\mathrm{ml}^{-1}$.

\section{Mortalitas Hama oleh B.bassiana pada 10 HSP}

Analisis ragam (Uji $\mathrm{F}$ ) menunjukkan bahwa kerapatan konidia dari cendawan B.bassiana berpengaruh terhadap mortalitas hama S.oryzae. Garis persamaan regresi polinomial yang dihasilkan pada 10 HSP adalah $\mathrm{y}=$ $0,4209 \mathrm{x}^{2}+14,38 \mathrm{x}+5,3044$ dengan $\mathrm{R}^{2}=$ 0,9792 (Gambar 6). Menurut persamaan tersebut, nilai mortalitas maksimum yang didapatkan adalah sebesar $128 \%$, sehingga $\mathrm{LC}_{50}$ dan $\mathrm{LC}_{95}$ dapat dicari. Konsentrasi yang efektif untuk mencapai $\mathrm{LC}_{50}$ adalah sebesar $1 \times 10^{3}$ konidia $\mathrm{ml}^{-1}$ dan konsentrasi yang efektif untuk mencapai $\mathrm{LC}_{95}$ adalah $1 \times 10^{8}$ konidia $\mathrm{ml}^{-1}$.

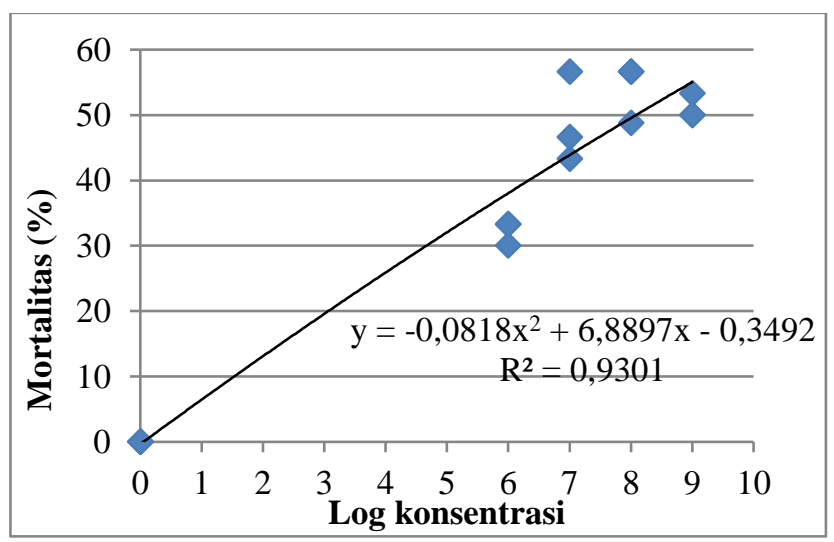

Gambar 5 Persamaan regresi pada 5 HSP pada pengujian cendawan B.bassiana 


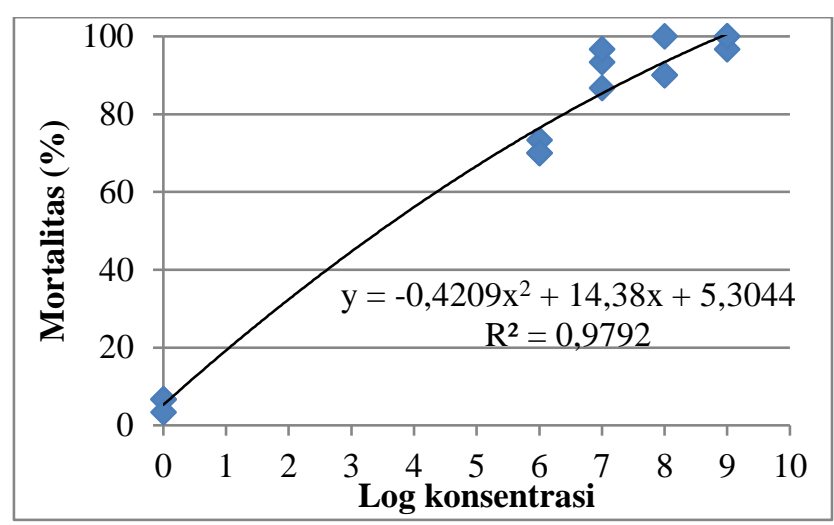

Gambar 6 Persamaan regresi pada 10 HSP pada pengujian cendawan B.bassiana

Isolat cendawan $M$. anisopliae maupun cendawan B. bassiana diinokulasi selama 21 hari di dalam inkubator dengan suhu $28^{\circ} \mathrm{C}$. Selama masa inokulasi dilakukan pembersihan cendawan pada media PDA dari kontaminasi Aspergillus sp dan bakteri. Pembersihan dilakukan 1-2 hari untuk mencegah penyebaran kontaminasi. Pembersihan kontaminasi dilaksanakan di ruang isolasi dengan cara membuang bagian PDA yang terkontaminasi menggunakan jarum ose yang telah dipanaskan terlebih dahulu.

Pembuatan suspensi kedua cendawan tersebut dilaksanakan di ruang isolasi dengan cara mengambil bagian konidia cendawan. Konidia tersebut dimasukkan ke dalam gelas ukur kemudian ditambahkan akuades steril dan tween 80 yang telah dicampur sebanyak $6 \mathrm{ml}$. Suspensi diaduk hingga rata kemudian disaring untuk mendapatkan suspensi yang jernih, suspensi tadi diteteskan pada haecytomer kemudian konidia dihitung dibawah mikroskop binokular.

Pengaplikasian kedua cendawan yang digunakan menunjukkankenaikan mortalitas hama seiring dengan peningkatan kerapatan konidia dan lama hari aplikasi (1-10 HSP). Dari pengujian tersebut dapat disimpulkan bahwa semakin tinggi tingkat kerapatan konidia yang digunakan, maka semakin efektif dalam mematikan hama. Hal ini sejalan dengan pendapat Suryadi dan Hendarsih (1991), bahwa semakin banyak jumlah konidia yang digunakan maka semakin banyak propagul jamur yang berfungsi sebagai agensia penularan sehingga semakin tinggi pula tingkat mortalitas kematian hama.

\section{KESIMPULAN}

Berdasarkan penelitian yang telah dilakukan, maka dapat disimpulkan bahwa semakin tinggi kerapatan konidia maka semakin tinggi pula tingkat kematian serangga S.oryzae. Cendawan B. bassiana memiliki pengaruh nyata dalam mematikan $S$. oryzae. Cendawan B. bassiana dalam waktu 10 HSP dapat mematikan hama S.oryzae sebesar 50\% (LC 50) dengan konsentrasi $1 \times 10$ konidia $\mathrm{ml}^{-1}$ dan dapat mematikan hama S.oryzae sebesar 95\% (LC 95) dengan konsentrasi 1 x $10^{8}$. Pada aplikasi menggunakan cendawan M.anisopliae tidak dapat dicari LC 50 dan LC 95, sehingga dapat disimpulkan bahwa cendawan B.bassiana lebih unggul dalam mematikan $S$. oryzae dibandingkan cendawan M.anisopliae.

\section{DAFTAR PUSTAKA}

ACIAR [Australian Centre for International Agricultural Research]. 2007. Guide to Fumigation Under Gas-Proof Sheets. http://www.aciar.gov.au [Diakses tanggal 18 Desember 2018].

Bari D. 2006. Keefektifan beberapa isolat cendawan entomopatogen 
Beauveria bassiana (BALSAMO) Vuillemin terhadap hama boleng Cylas formicarius (Fabr.) (COLEOPTERA: Curculionidae) di Laboratorium [Skripsi]. Bogor: Fakultas Pertanian, Institut Pertanian Bogor.

BPS [Badan Pusat Statistik] 2018. Survei Sosial Ekonomi Nasional. [Online] http://www.bps.go.id [Di akses 06 Desember 2018].

Desyanti, Hadi YS, Yusuf S, Santoso T. 2007. Keefektifan beberapa spesies cendawan entomopatogen untuk mengendalikan rayap tanah Coptotermes gestroi WASMANN (Isoptera: Rhinotermiditae) dengan metode kontak dan umpan. J. Ilmu dan Teknologi Кауu Tropis. 5(2): 68-77.

Lee PC, Hou RF. 2003. Phatogenesis of Metarhizium anisopliae van anisopliae in the smaller brown plant hopper Laodelphax striatelus. Chinese J. Entomol. (9):3-19.

Longstaff BC. 1981. Biology of the grain pest species of the genus Sitophilus (Coleoptera: Curculionidae): a crirical review. Protection Ecology. 2: 82-130.

Phillips TW, Throne JE. 2010. Bio-rational approaches to managing stored product. Annual Review of Entomology. 55:375-397.

Prijono D. 1985. Penuntun Praktikum Pestisida dan Alat Aplikasi. Bogor: Bagian Insektisida. IPB.

Riyanto, Santoso. 1991. Cendawan Beauveria bassiana dan Cara Pengendalian Guna Pengendalian Hama Bubuk Kopi. Jakarta: Direktorat Bina Perlindungan Tanaman Perkebunan.

Suryadi Y, Hendarsih S. 1991. Efektivitas campuran jamur patogen serangga M. Anisopliae dengan insektisida terhadap wereng coklat. Kumpulan Makalah Kongres IV PEI. Yogyakarta.

Wahyono TE, Tarrigan, N. 2007. Uji patogenisitas agen hayati Beauveria bassiana dan Metarhizium anisopliae terhadap ulat serendang (Xystrocera festiva). Buletin Teknik Pertanian. 12(1):22-29. 